\title{
Evaluasi Efek Samping Penggunaan Kombinasi Insulin pada Pasien Rawat Jalan Diabetes Melitus Tipe 2 di Salah Satu Rumah Sakit Kota Denpasar
}

\section{Side Effect Evaluation of Combination Use of Insulin in Outpatients with Type 2 Diabetes Mellitus in One of Hospital in Denpasar City}

\author{
Ni Nyoman Wahyu Udayani ${ }^{1 \bullet}$, Ni Luh Ayu Mega Ratnasari ${ }^{1}$, Erna Cahyaningsih ${ }^{2}$, I G.A.A. Kusuma Wardani ${ }^{2}$ \\ 1 Program Studi Sarjana Farmasi, Fakultas Farmasi, Universitas Mahasaraswati Denpasar, Kota Denpasar \\ 2Program Studi Diploma Tiga Farmasi, Fakultas Farmasi, Universitas Mahasaraswati Denpasar, Kota Denpasar
}

\begin{abstract}
Abstrak: Diabetes Melitus (DM) merupakan salah satu penyakit metabolik yang meningkat secara signifikan setiap tahun di Indonesia. World Health Organization (WHO) memprediksi kenaikan jumlah penyandang DM di Indonesia dari 8,4 juta pada tahun 2000 menjadi sekitar 21,3 juta pada tahun 2030. Banyaknya kasus DM di Indonesia serta penggunaan obat anti diabetes yang mengalami peningkatan dapat berpengaruh pada prevalensi terjadinya efek samping. Penelitian ini bertujuan untuk mengetahui efek samping pemberian kombinasi insulin pada pasien DM tipe 2 rawat jalan di salah satu Rumah Sakit Kota Denpasar. Penelitian ini merupakan jenis penelitian deskriptif dengan desain cross sectional secara retrospektif pada pasien DM tipe 2 yang menjalani rawat jalan di salah satu Rumah Sakit Kota Denpasar. Jumlah subjek yang diperoleh dalam penelitian ini adalah 65 orang yang memenuhi kriteria inklusi. Hasil penelitian menujukkan bahwa jumlah laki-laki $(58,5 \%)$ lebih banyak menderita DM tipe 2 dibandingkan perempuan $(41,5 \%)$. Usia terbanyak yang menderita DM tipe 2, yaitu pada rentang 55-65 tahun $(40 \%)$. Persentase tertinggi penderita DM tipe 2 pada tingkat pendidikan menengah (SMA) (38,5\%). Efek samping yang diperoleh pada pemberian kombinasi insulin pada pasien DM tipe 2 di salah satu Rumah Sakit Kota Denpasar yaitu pusing (38,5\%), lemas (32,3\%), berdebar $(12,4 \%)$, berkeringat $(4,6 \%)$, gemetar dan hipoglikemia masing-masing $(6,15 \%)$. Dari data tersebut dapat disimpulkan bahwa keluhan yang dialami disebabkan oleh timbulnya gejala serta tanda dari adanya efek samping penggunaan insulin yaitu hipoglikemia.
\end{abstract}

Kata Kunci: diabetes melitus tipe 2, efek samping insulin, kombinasi insulin.

\begin{abstract}
Diabetes Mellitus (DM) is a metabolic disease that increases significantly every year in Indonesia. The World Health Organization (WHO) predicts an increase in the number of people with diabetes in Indonesia from 8.4 million in 2000 to around 21.3 million in 2030. The number of DM cases in Indonesia and the increasing use of anti-diabetic drugs can affect the prevalence of this effect. side. This study aims to determine the side effects of administering a combination of insulin in outpatient type 2 DM patients at a hospital Denpasar Regency. This study is a descriptive type of research with a retrospective cross sectional design in type 2 DM patients undergoing outpatient treatment at a hospital Denpasar Regency. The number of subjects obtained in this study were 65 people who met the inclusion criteria. The results showed that the number of men (58.5\%) suffered from type 2 diabetes more than women (41.5\%). The most age who suffer from type $2 \mathrm{DM}$, which is in the range of 55-65 years (40\%). The highest percentage of patients with type $2 \mathrm{DM}$ was at the secondary education level (SMA) (38.5\%). The side effects obtained from administering a combination of insulin to type 2 DM patients at a hospital in Denpasar Regency are dizziness (38.5\%), weakness (32.3\%), palpitations (12.4\%), sweating (4, $6 \%)$, shaking and hypoglycemia (6.15\% respectively). From these data it can be concluded that the complaints experienced are caused by the onset of symptoms and signs of side effects of insulin use, namely hypoglycemia.

Keywords: type 2 diabetes mellitus, insulin combination, insulin side effect.
\end{abstract}

\footnotetext{
•email korespondensi: udayani.wahyu@unmas.ac.id
} 


\section{PENDAHULUAN}

Diabetes Melitus (DM) atau yang sering disebut kencing manis adalah suatu gangguan kronis yang ditandai dengan terjadinya hiperglikemia (meningkatnya glukosa darah) karena terganggunya metabolisme glukosa di dalam tubuh. World Health Organization $(W H O)$ memprediksi kenaikan jumlah penyandang DM di Indonesia dari 8,4 juta pada tahun 2000 menjadi sekitar 21,3 juta pada tahun 2030. Laporan ini menunjukkan adanya peningkatan jumlah penyandang DM sebanyak 2-3 kali lipat pada tahun 2035. International Diabetes Federation (IDF) juga memprediksi adanya kenaikan jumlah penyandang DM di Indonesia dari 9,1 juta pada tahun 2014 menjadi 14,1 juta pada tahun 2035 (Perkumpulan Endrokrinologi Indonesia (PERKENI), 2015).

Secara umum, hampir $80 \%$ prevalensi DM adalah DM tipe 2 (Putra, Achmad and P., 2017). Rumah Sakit X di Kota Denpasar merupakan salah satu rumah sakit dengan jumlah pasien DM tipe 2 yang cukup banyak dan penyakit ini memiliki kedudukan tertinggi dari 10 besar penyakit yang ada dan penderitanya selalu bertambah tiap tahunnya.

Penatalaksanaan DM secara umum terdapat 4 pilar yaitu edukasi, terapi gizi, latihan jasmani, dan intervensi farmakologis. Intervensi farmakologis terdiri dari obat antihiperglikemik oral dan insulin. Terapi insulin pada penderita DM tipe 2 diperlukan ketika terjadi resistensi insulin, diabetes sudah tidak terkendali, serta pengobatan dengan kombinasi Obat Hiperglikemik Oral (OHO) dosis optimal gagal.

Berdasarkan lama kerjanya, sediaan insulin dibedakan menjadi empat jenis, yaitu insulin kerja cepat, insulin kerja pendek, insuli kerja sedang, dan insulin kerja panjang. Untuk mencapai sasaran glukosa darah basal dipergunakan insulin kerja sedang atau panjang (insulin basal), sedangkan untuk mencapai target nilai $\mathrm{HbA1c}$ akan diberikan insulin kerja cepat atau insulin kerja pendek (insulin prandial) (Perkumpulan Endrokrinologi Indonesia (PERKENI), 2015).

Kombinasi antara insulin kerja cepat dengan insulin kerja panjang yang diberikan penderita DM tipe 2 diupayakan mampu meniru pola sekresi insulin fisiologis. Terapi dengan kombinasi insulin sering menimbulkan reaksi obat yang merugikan (ROM) yang berupa efek samping. Efek samping yang paling sering dan umum terjadi yaitu hipoglikemia (gula darah rendah). Pasien yang menggunakan insulin dapat mengalami hipoglikemia dari ringan, yang dapat ditangani sendiri sampai hipoglikemia berat yang membutuhkan bantuan orang lain untuk mendapatkan kembali kadar gula darah normal. Hipoglikemia berat minimal terjadi sekali per tahun sebesar $27 \%$ pada pasien yang diobati regimen insulin intensif. Hipoglikemia merupakan penyebab kematian pada sekitar 3\% dari penderita diabetes mellitus yang bergantung pada insulin (Pelle, 2016). Efek samping obat dapat memperburuk keadaan pasien, untuk itu harus dilakukan pemantauan atau monitoring efek samping obat. Efek samping obat sering juga dikaitkan dengan lamanya penggunaan obat.

Berdasarkan uraian di atas dan banyaknya kasus DM di Indonesia serta penggunaan obat anti diabetes mengalami peningkatan yang dapat berpengaruh pada prevalensi terjadinya efek samping, maka peneliti tertarik melakukan penelitian mengenai "Evaluasi Efek Samping Penggunaan Kombinasi Insulin pada Pasien Rawat Jalan Diabetes Melitus Tipe 2 di salah satu Rumah Sakit Kota Denpasar".

\section{METODE PENELITIAN}

\section{Rancangan Penelitian}

Penelitian ini menggunakan metode penelitian noneksperimental deskriptif, yang dilakukan secara retrospektif, yaitu diambil dari penelusuran data rekam medis pasien yang didapatkan di bagian Instalasi Rekam Medis Rumah Sakit X di Denpasar. Penelitian ini dilaksanakan dari pada tahun 2019.

\section{Subjek Penelitian}

Subjek penelitian adalah rekam medis pasien Diabetes Melitus tipe 2 yang melakukan rawat jalan di Rumah Sakit X Kota Denpasar yang mendapatkan terapi kombinasi insulin yang memenuhi kriteris inklusi.

1. Adapun kriteria inklusi dalam penelitian ini yaitu, pasien diabetes melitus berumur diatas 17 tahun 
yang menggunakan kombinasi insulin di rumah sakit X Denpasar periode tahun 2019.

2. Adapun kriteria eksklusi dalam penelitian ini yaitu rekam medis pasien yang tidak lengkap/ rekam medis yang hilang.

Dari data diperoleh pasien DM tipe 2 sebanyak 65 pasien yang memenuhi kriteria inklusi.

\section{Teknik Pengumpulan Data}

Dilakukan secara sekunder yaitu dengan analisis data rekam medis pasien. Data yang diambil diantaranya nama, nomor rekam medis, jenis kelamin, umur, obat yang diberikan, diagnosa pasien, dan keluhan pasien selama terapi.

\section{Analisis Data}

Data yang diperoleh selama penelitian yang terdiri dari nomor rekam medik, nama pasien, umur, jenis kelamin, pendidikan, kombinasi insulin yang digunakan, dosis, diagnosa serta keluhan pasien selama terapi. Data tersebut disajikan dalam bentuk tabel dan dianalisis secara deskriptif, dengan menghitung jumlah dan persentase kejadian efek samping, mencari penyebab terjadinya efek samping yang dialami oleh pasien di rumah sakit X Kota Denpasar

\section{HASIL DAN PEMBAHASAN}

\section{Karakteristik Subjek Penelitian Berdasarkan Jenis} Kelamin.

Persentase jumlah subjek berdasarkan jenis kelamin pada pasien DM tipe 2 rawat jalan di RS X di Denpasar dapat dilihat pada tabel 1 . Jumlah pasien DM tipe 2 lebih banyak diderita oleh laki-laki yaitu sejumlah 38 orang dengan persentase $58,5 \%$. Hasil penelitian ini sejalan dengan peneitian yang dilakukan oleh Wiracana, (2017) bahwa prevalensi DM lebih besar pada laki-laki daripada perempuan. Hal ini dapat dijelaskan karena laki-laki mempunyai tingkat stres lebih besar dibandingkan dengan perempuan. Stres yang akut cenderung meningkatkan kadar glukosa darah. Stres emosional dapat mempengaruhi gula darah dalam beberapa cara. Manifestasi stres yang paling sering adalah diakibatkan oleh kenaikan dalam hormon stres yang bersikulasi dalam darah. Hormon stres seperti epineprin atau adrenalin dan kortisol, melepaskan glukosa yang disimpan dalam darah, akibatnya adalah kenaikan kadar gula darah yang sering menyebabkan peningkatan insulin (Udayani, Meriyani and Wardani, 2018).

Tabel 1. Karakteristik Pasien DM tipe 2 Berdasarkan Jenis Kelamin

\begin{tabular}{cccc}
\hline No & $\begin{array}{c}\text { Jenis } \\
\text { Kelamin }\end{array}$ & Jumlah & $\begin{array}{c}\text { Persentase } \\
\text { (\%) }\end{array}$ \\
\hline 1 & Laki-Laki & 38 & 58,5 \\
2 & Perempuan & 27 & 41,5 \\
\hline & Total & $\mathbf{6 5}$ & $\mathbf{1 0 0 , 0}$ \\
\hline
\end{tabular}

\section{Karakteristik Subjek Penelitian Berdasarkan Umur.}

Persentase jumlah subjek berdasarkan umur pada pasien DM tipe 2 rawat jalan di RS X Kota Denpasar dapat dilihat pada tabel 2. Jumlah pasien DM tipe 2 lebih banyak diderita oleh pasien dengan rentang umur 56-65 tahun yaitu sejumlah 26 orang dengan persentase $40 \%$. Hasil penelitian ini sama dengan penelitian yang dilakukan oleh Pasaribu (2014). Menurut Lailatul, 2017 dalam penelitiannya menyebutkan prevalensi DM tipe 2 akan meningkat seiring dengan meningkatnya umur dan mengakibatkan semakin tinggi pula gangguan toleransi glukosa. Banyaknya penderita DM tipe 2 pada umur diatas 50 tahun karena pada seseorang yang berusia lebih dari 50 tahun dengan pengaturan diet glukosa yang rendah akan mengalami penyusutan sel-sel beta pankreas. Sel beta pankreas yang tersisa pada umumnya masih aktif, tetapi sekresi insulinnya semakin berkurang. Pada umur ini umumnya manusia mengalami penurunan fungsi fisiologis dengan cepat, sehingga terjadi defisiensi sekresi insulin karena gangguan pada sel beta pankreas dan resistensi insulin (Khotimah K, 2013).

Tabel 2. Karakteristik Pasien DM tipe 2 Berdasarkan Umur

\begin{tabular}{cccc}
\hline No & Umur (Th) & Jumlah & $\begin{array}{c}\text { Persentase } \\
(\%)\end{array}$ \\
\hline $\mathbf{1}$ & $17-25$ & 2 & 3,1 \\
$\mathbf{2}$ & $26-35$ & 1 & 1,5 \\
$\mathbf{3}$ & $36-45$ & 5 & 7,7 \\
$\mathbf{4}$ & $46-55$ & 16 & 24,6 \\
$\mathbf{5}$ & $56-65$ & 26 & 40,0 \\
$\mathbf{6}$ & $>65$ & 15 & 23,1 \\
\hline & Total & $\mathbf{6 5}$ & $\mathbf{1 0 0 , 0}$ \\
\hline
\end{tabular}


Karakteristik Subjek Penelitian Berdasarkan Tingkat Pendidikan.

Persentase jumlah subjek berdasarkan tingkat pendidikan pada pasien DM tipe 2 rawat jalan di RS X Kota Denpasar dapat dilihat pada tabel 3. Jumlah pasien DM tipe 2 berdasarkan tingkat pendidikan yang tertinggi adalah pada tingkat SMA yaitu sebanyak 38,5\%. Pengetahuan seseorang dipengaruhi oleh tingkat pendidikan. Pengetahuan mempengaruhi seseorang dalam mengambil keputusan untuk berperilaku sehat. Tingkat pendidikan yang lebih rendah dikaitkan dengan meningkatnya risiko terkena penyakit DM tipe 2 dan komplikasinya (Sacerdote et al., 2012). Tingginya prevalensi penderita dengan tingkat pendidikan menengah mungkin berhubungan dengan tingkat kesadaran yang rendah untuk memperoleh pengobatan (Pasaribu, 2014).

Tabel 3. Karakteristik Pasien DM tipe 2 Berdasarkan Tingkat Pendidikan

\begin{tabular}{cccc}
\hline No & $\begin{array}{c}\text { Tingkat } \\
\text { Pendidikan }\end{array}$ & Jumlah & $\begin{array}{c}\text { Persentase } \\
(\%)\end{array}$ \\
\hline 1 & Tidak Sekolah & 2 & 3,1 \\
2 & SD & 14 & 21,5 \\
3 & SMP & 12 & 18,5 \\
4 & SMA & 25 & 38,5 \\
5 & D1 & 4 & 6,1 \\
6 & Sarjana & 8 & 12,3 \\
\hline & Total & $\mathbf{6 5}$ & $\mathbf{1 0 0 , 0}$ \\
\hline
\end{tabular}

\section{Karakteristik Subjek Penelitian Berdasarkan Diagnosa Penyakit.}

Persentase jumlah subjek berdasarkan diagnosa penyakit pada pasien DM tipe 2 rawat jalan di RS X di Kota Denpasar dapat dilihat pada tabel 4 . Jumlah pasien DM tipe 2 dengan komplikasi lebih tinggi yaitu sebanyak 52,3\% dibandingankan dengan pasien DM tipe 2 tanpa komplikasi. Diabetes yang terjadi dari waktu ke waktu dan tidak terkontrol secara baik dapat menyebabkan kerusakan berbagai sistem tubuh terutama syaraf dan pembuluh darah. Selain itu gaya hidup, terutama konsumsi makanan yang tidak sehat serta kurangnya aktivitas fisik dapat menjadi penyebab timbulnya komplikasi pada penderita DM tipe 2 (Udayani and Meriyani, 2016).
Beberapa komplikasi yang sering terjadi adalah meningkatnya risiko penyakit jantung dan stroke, neuropati, retinopati, penyebab utama gagal ginjal serta resiko kematian (Riset Kesehatan Dasar, 2013).

Tabel 4. Karakteristik Pasien DM tipe 2 Berdasarkan Diagnosa Penyakit

\begin{tabular}{clcc}
\hline No & \multicolumn{1}{c}{$\begin{array}{c}\text { Diagnosa } \\
\text { Penyakit }\end{array}$} & Jumlah & $\begin{array}{c}\text { Persentase } \\
\text { (\%) }\end{array}$ \\
\hline Diabetes Melitus & 31 & 47,7 \\
1 & $\begin{array}{l}\text { Tipe 2 Tanpa } \\
\text { Komplikasi }\end{array}$ & 31 & \\
& $\begin{array}{l}\text { Diabetes Melitus } \\
\text { Tipe 2 Dengan } \\
\text { Komplikasi }\end{array}$ & 34 & 52,3 \\
\hline$\quad$ Total & $\mathbf{6 5}$ & $\mathbf{1 0 0 , 0}$ \\
\hline
\end{tabular}

\section{Karakteristik Subjek Penelitian Berdasarkan Komplikasi.}

Persentase jumlah subjek berdasarkan komplikasi pada pasien DM tipe 2 rawat jalan di RS $X$ di Kota Denpasar dapat dilihat pada tabel 5. Jumlah pasien DM tipe 2 berdasarkan karakteristik komplikasi terlihat bahwa pasien dengan komplikasi neuropati paling banyak ditemukan yaitu sebesar $58,8 \%$. Hasil penelitian ini sejalan dengan data Riset Kesehatan Dasar (Riset Kesehatan Dasar, 2013). Hal ini terjadi karena kadar gula darah yang tinggi mengakibatkan serat saraf hancur sehingga sinyal ke otak dan dari otak tidak terkirim dengan benar, akibat dari tidak terkirimnya sinyal tersebut maka hilangnya indera perasa, meningkatnya rasa nyeri di bagian yang terganggu. Kerusakan saraf tepi yang umum terjadi biasanya dimulai dari jempol kaki hingga seluruh kaki dan akan timbul mati rasa. Keluhan yang paling sering dirasakan adalah kesemutan (Kariadi, 2009). Selain neuropati sebanyak 41,2\% penderita DM tipe 2 mengalami komplikasi lain seperti hipertensi. Menurut Hongdiyanto, 2013, hipertensi disebabkan karena kadar gula darah yang terlalu tinggi dan dapat merusak organ jaringan pembuluh darah serta dapat terbentuknya aterosklerosis, hal tersebut menyebabkan arteri menyempit dan sulit mengembang sehingga memicu timbulnya hipertensi. 
Tabel 5. Karakteristik Pasien DM tipe 2 Berdasarkan Komplikasi

\begin{tabular}{cccc}
\hline No & Komplikasi & Jumlah & $\begin{array}{c}\text { Persentase } \\
\text { (\%) }\end{array}$ \\
\hline 1 & $\begin{array}{l}\text { DM Tipe 2 }+ \\
\text { Neuropati }\end{array}$ & 20 & 58,8 \\
2 & $\begin{array}{l}\text { DM Tipe 2 }+ \\
\text { Hipertensi }\end{array}$ & 14 & 41,2 \\
\hline & Total & $\mathbf{3 4}$ & $\mathbf{1 0 0 , 0}$ \\
\hline
\end{tabular}

Karakteristik Subjek Penelitian Berdasarkan Terapi Pengobatan.

Persentase jumlah subjek berdasarkan terapi pengobatan pada pasien DM tipe 2 rawat jalan di RS X di Kota Denpasar dapat dilihat pada tabel 6 . Jumlah pasien DM tipe 2 yang menerima terapi kombinasi insulin novorapid dengan levemir lebih banyak dibandingkan dengan terapi kombinasi novorapid dengan lantus yakni sebesar $78,5 \%$. Pemilihan suatu kombinasi insulin didasarkan pada profil kerjanya untuk dapat meniru pola sekresi insulin normal tubuh (Dipiro et al., 2014). Kombinasi insulin novorapid dengan levemir dan novorapid dengan lantus memberikan onset dan durasi kerja yang sama yakni onset kerja yang cepat dengan durasi kerja yang lebih panjang sehingga lebih dapat meniru profil insulin normal tubuh (Kartika, Lestari and Swastini, 2013). Apabila dibandingkan levemir (insulin detemir) memiliki keuntungan mengurangi risiko hipoglikemia berat dan nokturnal, dibandingkan dengan lantus (insulin glargine) selain itu kenaikan berat badan rata-rata lebih rendah dengan kelompok detemir, yaitu 2,8 $\mathrm{kg}$ berbanding $3,8 \mathrm{~kg}$ dari pada kelompok glargine (Poon and King, 2010).

Tabel 6. Karakteristik Pasien DM tipe 2 Berdasarkan Terapi Pengobatan

\begin{tabular}{clcc}
\hline No & $\begin{array}{l}\text { Terapi } \\
\text { Pengobatan }\end{array}$ & Jumlah & $\begin{array}{c}\text { Persentase } \\
\text { (\%) }\end{array}$ \\
\hline 1 & $\begin{array}{l}\text { Novorapid }+ \\
\text { Levemir }\end{array}$ & 51 & 78,5 \\
2 & $\begin{array}{l}\text { Novorapid }+ \\
\text { Lantus }\end{array}$ & 14 & 21,5 \\
\hline & Total & $\mathbf{6 5}$ & $\mathbf{1 0 0 , 0}$ \\
\hline
\end{tabular}

\section{Samping.}

Persentase jumlah subjek berdasarkan efek samping pada pasien DM tipe 2 rawat jalan di RS $X$ di Kota Denpasar dapat dilihat pada tabel 7. Jumlah pasien DM tipe 2 yang mengalami keluhan berupa pusing sebesar $38,5 \%$, pasien dengan keluhan lemas sebesar 32,3\%, pasien dengan keluhan berdebar sebesar $12,4 \%$, pasien dengan keluhan gemetar dan hipoglikemia masing masing sebesar $6,1 \%$, serta pasien dengan keluhan berkeringat sebesar $4,6 \%$. Keluhan yang dirasakan oleh pasien dapat disebabkan oleh timbulnya gejala serta tanda dari hipoglikemia. Menurut Martindale 2009, efek samping terapi insulin yang paling sering adalah hipoglikemia. Gejala hipoglikemia akibat peningkatan aktivitas simpatis termasuk kelaparan, pucat, berkeringat, jantung berdebar, cemas, dan gemetaran. Gejala lain termasuk pusing, sakit kepala, gangguan penglihatan seperti penglihatan kabur atau ganda, bicara tidak jelas, parestesia mulut dan jari, perubahan perilaku, dan gangguan kemampuan mental atau intelektual. Kecepatan onset dan lamanya dapat bervariasi sesuai dengan jenis persiapan dan rute yang digunakan. Biasanya dikaitkan dengan dosis insulin yang berlebihan, pengurangan makan oleh pasien, atau peningkatan aktivitas fisik (Martindale, 2009).

Tabel 7. Karakteristik Pasien DM tipe 2 Berdasarkan Efek Samping

\begin{tabular}{cccc}
\hline No & Efek Samping & Jumlah & $\begin{array}{c}\text { Persentase } \\
\text { (\%) }\end{array}$ \\
\hline 1 & Pusing & 25 & 38,5 \\
2 & Lemas & 21 & 32,3 \\
3 & Berkeringat & 3 & 4,6 \\
4 & Berdebar & 8 & 12,4 \\
5 & Gemetar & 4 & 6,1 \\
6 & Hipoglikemia & 4 & 6,1 \\
\hline & Total & $\mathbf{6 5}$ & $\mathbf{1 0 0 , 0}$ \\
\hline
\end{tabular}

\section{SIMPULAN}

Dari hasil penelitian yang dilakukan dapat disimpulkan bahwa keluhan yang dialami oleh pasien DM tipe 2 yang menggunakan terapi kombinasi insulin di salah satu Rumah sakit di Kota Denpasar yaitu pusing sebanyak $38,5 \%$, lemas sebanyak $32,3 \%$, 
berdebar sebanyak 12,4\%, gemetar dan hipoglikemia masing masing sebanyak 6,1\%, serta berkeringat sebanyak $4,6 \%$ disebabkan oleh timbulnya gejala serta tanda dari adanya efek samping penggunaan insulin yaitu hipoglikemia.

\section{UCAPAN TERIMA KASIH}

Peneliti mengucapkan terimakasih kepada kepala Rumah Sakit yang telah memberikan izin serta petugas instalasi rekam medis dan petugas instalasi farmasi yang telah membantu jalannya penelitian ini.

\section{DAFTAR PUSTAKA}

Dipiro, J. T. et al. (2014) Pharmacotherapy: a pathophysiologic approach. 7th edn. New York: McGraw-Hill.

Kariadi, S. H. K. S. (2009) Diabetes? Siapa takut!! Panduan Lengkap untuk Diabetes, Keluarganya, dan Profesional Medis. Bandung: PT. Mizan Pustaka.

Kartika, I. G. A. ., Lestari, A. A. . and Swastini, D. A. (2013) 'Perbandingan Profil Penggunaan Terapi Kombinasi Insulin pada Pasien Diabetes Mellitus Tipe 2 di Unit Rawat Inap Rumah Sakit Umum Pusat Sanglah', Jurnal Farmasi Udayana, 2(2), pp. 62-69.

Martindale (2009) Martindale: The Complete Drug Reference. 36th edn. Edited by S. C. Sweetman. London; Chicago: Pharmaceutical Press.

Pasaribu, S. (2014) 'DISTRIBUSI UMUR, JENIS KELAMIN, TINGKAT PENDIDIKAN, PEKERJAAN DAN JENIS KOMPLIKASI PADA PENDERITA DM TIPE 2 DENGAN KOMPLIKASI YANG DIRAWAT INAP DI RSUD DR. PIRNGADI MEDAN TAHUN 2012'.

Pelle, C. (2016) 'HUBUNGAN PENGETAHUAN PENGGUNAAN INSULIN DENGAN HIPOGLIKEMIA PADA PASIEN DIABETES MELITUS PANCARAN KASIH MANADO', 4(November).
Perkumpulan Endrokrinologi Indonesia (PERKENI) (2015) Pengelolaan dan pencegahan diabetes melitus di Indonesia. doi: 10.1017/CBO9781107415324.004.

Poon, K. and King, A. B. (2010) 'Glargine and detemir : Safety and efficacy profiles of the long-acting basal insulin analogs', pp. 213223. doi: 10.2147/DHPS.S7301.

Putra, R. J. S., Achmad, A. and P., H. R. (2017) 'Kejadian Efek Samping Potensial Terapi Obat Anti Diabetes Pasien Diabetes Melitus Berdasarkan Algoritma Naranjo', Pharmaceutical Journal of Indonesia, 2(2), pp. 45-50.

Riset Kesehatan Dasar (2013). Jakarta: Badan Penelitian dan Pengembangan Kesehatan, Kementerian Kesehatan Republik Indonesia.

Sacerdote, C. et al. (2012) 'Lower educational level is a predictor of incident type 2 diabetes in European countries: The EPIC-InterAct study', International Journal of Epidemiology, 41(4), pp. 1162-1173. doi: 10.1093/ije/dys091.

Udayani, N. N. W. and Meriyani, H. (2016) 'PERBEDAAN EFEKTIVITAS PENGGUNAAN OBAT ANTIDIABETIK ORAL TUNGGAL DENGAN KOMBINASI PADA PASIEN DM TIPE 2 DI UPT. PUSKESMAS DAWAN II KABUPATEN KLUNGKUNG PERIODE NOVEMBER 2015-PEBRUARI 2016', Jurnal Ilmiah Medicamento, 2(2), pp. 47-52. doi: 10.36733/MEDICAMENTO.V2I2.1096.

Udayani, N. N. W., Meriyani, H. and Wardani, I. G. A. A. K. (2018) 'ANALISIS EFEKTIVITAS BIAYA MEDIS LANGSUNG PENGGUNAAN INSULIN DAN INSULIN KOMBINASI OHO PADA PASIEN DM TIPE 2 RAWAT JALAN DI RSUP SANGLAH DENPASAR', Jurnal Ilmiah Medicamento, 4(1), pp. 18-24. doi: 10.36733/medicamento.v4i1.874.

Wiracana, M. (2017) 'ANALISIS EFEKTIVITAS BIAYA PENGGUNAAN INSULIN PADA PASIEN DIABETES MELITUS TIPE 2 RAWAT JALAN DI RUMAH SAKIT KOTA DENPASAR'. 